\title{
Nepal Tourism Year 2011
}

\section{Background}

The Government of Nepal in consultation and comprehending the voice of the Nepalese tourism stakeholders decided on October 25, 2008 to launch a national tourism campaign "Nepal Tourism Year 2011 (NTY 2011)". The announcement of the campaign reflects the recognition of the tourism sector as one of the economic mainstays of the Nepalese economy by the government. It is also analogical to the various interactions and consensus among the Ministry of Tourism and Civil Aviation (MoTCA), the Nepal Tourism Board (NTB), tourism entrepreneurs and other stakeholders in launching a special tourism promotion campaign, in order to further enhance the image of Nepal as a safe and pleasant tourist destination in the international tourism arena.

With the badge of adventure destination glittering and the adage "Atithi Devo Bhava" (Guests are Gods) embedded in our culture, the assortment of our tourism products never ceases to mesmerise the visitors from around the world. The unparalleled and unique cultural, geographical, ethnic and bio diversities of the country allure visitors to Nepal time and again, which truly substantiates the spirit of the Nepalese tourism brand "Naturally Nepal, once is not enough!"

The essence of tourism and its role lies in contributing to economic growth, poverty alleviation and overall social development. The NTY 2011 envisions harnessing these opportunities and strengths and bringing together the commitment of the government, expertise and experiences of organizations like the NTB, aptitude and dynamism of the private sector and aspirations of the local communities for further development of tourism in the country. Representation and active participation from awide spectrum of tourism stakeholders is taken into prominence in order to make the campaign inclusive and participatory in modus operandi and effective in delivering results. The campaign will also focus on mobilizing the networks of the Non-Resident Nepalese (NRN) communities, Nepalese diplomatic missions abroad, non-governmental organisations, airline companies and the media. Similarly, friends and well-wishers of Nepal, tourism academicians and celebrities are approached in order to highlight the campaign internally and internationally.

\section{Quantified Targets (Output)}

The primary goal of the campaign is to bring in one million international tourists to Nepal, almost double of the current figure of slightly over half a million tourists in a year, in 2011. Apart from this overarching goal, the campaign targets to: 
1. At least $40 \%$ of the international tourists travelling beyond the present tourism sites.

2. Encourage additional investment on tourism infrastructures by $50 \%$.

3. Promote and maintain the record of domestic tourism.

The campaign seeks to accomplish these outputs by adopting appropriate strategic interventions in partnership with the concerned tourism stakeholders. Diversifying the tourism products, capacity building of tourism stakeholders, enhancing air and land connectivity, exploring new tourism segments and focusing on the regional markets with right product and promotional mix are the planned strategic moves during the campaign.

\section{Institutional Arrangements}

\section{Main Organising Committee:}

Considering the magnitude of the campaign, the Government of Nepal has formed the Main Organising Committee with the Honourable Minister for Tourism and Civil Aviation as its convener. . The committee boasts 61 members, which also includes the Honourable Vice Chairman of National Planning Commission serving as its joint convener. The Secretaries of various line Ministries; Chiefs of Metropolitan, Sub-Metropolitan cities and Municipalities; travel and trade associations serve as the members. The Chief Executive Officer (CEO) of NTB has been designated as the Member-Secretary of the committee.

\section{Scope of work}

The Main Organising Committee has been authorised to carry out tourism programmes and activities within the following Terms of Reference:

1. The Committee may draft working modalities by itself.

2. The Committee shall prepare and determine the programs for NTY 2011.

3. The Committee shall form sub-committees and task forces as and when required.

4. The Committee shall draft an action plan and budget estimate and submit to the Government of Nepal.

5. The Committee shall prepare and design the promotional slogan and logo of the campaign.

6. It shall obtain and mobilize political, governmental, non-governmental and foreign support and resources.

7. The Committee shall allocate a separate fund to finance the programme and activities (Funds shall be collected from government, non-governmental and other sources). 
8. The Committee shall establish its secretariat.

9. The Committee shall prepare the human resource requirement at the secretariat and submit to the Government of Nepal for approval.

\section{Program Implementation Sub-Committee}

To implement the decision of the Main Organising Committee and to ensure maximum participation from the private sector, communities and other stakeholders, a programme implementation sub-committee has been formed under the Chairmanship of the Secretary, MoTCA and Yogendra Shakya as its convener. While the membership at the Main Organising Committee is based on institutional representation, most of the members of this committee, including the convener are individual tourism entrepreneurs.

\section{Functional Sub-Committees}

The Main Organising Committee of NTY 2011 has formed the following 14 thematic sub-committees. These sub-committees are mandated to draft and implement specific strategies, programmes and activities. Each sub-committee is required to be headed by a private sector entrepreneur, high ranking government official or tourism expert in the concerned field. The purposes behind forming these subcommittees are to rope in necessary support and contribution from all relevant sectors and agencies related to tourism and to encourage wider participation from tourism stakeholders.

1. Policy Advocacy

2. Physical Infrastructure and Coordination

3. Product Improvement and Development

4. Events, Festivals and Activities

5. Marketing, Promotion and Publicity

6. Human Resource and Capacity Building

7. Aviation and Transport Coordination

8. Resources Mobilization and Monitoring

9. Natural and Culture Heritage

10. Political Coordination

11. Crisis Management and Security Coordination

12. Mountain Tourism Coordination

13. Legal Affairs Coordination

14. Diplomatic Affairs Coordination 


\section{Regional Sub-Committees}

Besides the above mentioned thematic sub-committees, there are five regional sub-committees in each of the five development regions of Nepal. Headed by the Regional Administrator, each regional sub-committee includes representatives of political parties, local tourism entrepreneurs, Local Development Officer, security officials and media personnel as its members.

\section{Secretariat}

The NTB has been entrusted to function as a secretariat of NTY 2011 as per the decision of the cabinet. A senior director serves as the Member Secretary to the Program Implementation Committee who looks after the administrative and dayto-day affairs related to the campaign.

\section{Present Status}

It is observed that the Main Organising Committee and the Program Implementation Sub-Committee have been working in close association with the relevant tourism stakeholders in order to achieve the targets and objectives of NTY 2011. National and international tourism promotion programmes are underway in partnerships with the government bodies, the NTB, private sector, Nepali diplomatic missions abroad and NRN communities in line with the new slogan of the campaign "Together for Tourism". 